\title{
A mulher na vida e na obra de Nietzsche*
}

\author{
Mario de Lima**
}

\begin{abstract}
Resumo: Artigo publicado em 1922, no periódico A.B.C. Nesse texto, que é um trecho do livro Ideias e Comentários, Mario de Lima aborda o papel exercido pela mulher na vida e na obra de Nietzsche, em particular a relação do filósofo com a mãe, a irmã Elisabeth e a amiga Malwida von Meysenbug.

Palavras-chave: Nietzsche - mulher - mãe - irmã - Malwida von Meysenbug
\end{abstract}

Quase todas as ideias de Nietzsche sobre o amor e sobre a mulher são reflexos da obra de Schopenhauer. Como observa Schuré, o lírico impetuoso e transbordante do Super-homem no crê no idealismo, na intuição, no senso divinatório da mulher, embora superior; nesse "algo de divino" que lhe atribuam os germanos de Tácito. Como explicar as prevenções de Nietzsche contra a Mulher? Haveria sinceridade em seus juízos depreciativos sobre a mais bela metade da espécie humana? Ou seriam fruto de desrespeito de um coração incompreendido e desprezado os conceitos menos gentis que semeou em toda a sua obra?

Albertina Bertha, em sua apaixonada e flamante apologia de Nietzsche, escreve: "Nietzsche não teve de nós outras, mulheres,

* Trecho de um capítulo do livro "Ideias e Comentários", publicado no periódico A.B.C. Rio de Janeiro, ano 08, N. 383, 08 de Julho de 1922, p. 08.

** Mario Franzen de Lima (1886-1936). Poeta, ensaísta, polemista e jurista, formado em Direito pela Faculdade de Direito de Minas Gerais. 
uma opinião cabal, exata; apenas beirou a realidade da nossa estrutura moral. As suas referências são sombras ocas, ironias para provocar o sorriso, ou, talvez, vinganças de despeitado, floração de mau humor... São chicotadas de quem nunca foi amado, de quem nunca recebeu o carinho, a meiguice, a febre de uma mulher de espírito e de beleza".

Verifiquemos até que ponto pode ser isso verdade. Cinco figuras femininas principais enchem de encantos e de amarguras a existência atribulada do filósofo alemão. São elas: sua mãe, sua irmã Lisbeth, Cosima Wagner e mademoiselles Meysenbug e Lou-Andréas-Salomé. Que influência exerceu cada uma dessas mulheres na vida de Nietzsche? Façamo-las desfiar, uma por uma. Elas formam, por assim dizer, o pentágono estrelado do seu destino afetivo.

Nietzsche era filho do pastor protestante Karl-Ludwig Nietzsche. Tinha apenas três anos, quando seu pai, vítima de uma queda, perdeu a razão, falecendo um ano depois. Ei-lo órfão aos quatro anos. Dez anos depois ele descrevia a dolorosa impressão que lhe ficara desses dias trágicos de luto:

Nossa família tinha sido despojada de sua coroa, toda a alegria desapareceu de nossos corações e uma tristeza profunda apoderou-se de nós. Narra, em seguida, o sonho premonitório, que lhe anunciara o fim de seu irmão José.

Contei pela manhã esse sonho à minha mãe bem amada. Pouco depois, meu irmão caiu doente, teve ataques de nervos e morreu em poucas horas. Nossa mágoa foi terrível. Realizara-se exatamente meu sonho. Após essa dupla desgraça, o Senhor nos foi todo o nosso consolo.

Minha mãe bem amada, escrevia Nietzsche aos quatorze anos. Esse amor filial, cheio de ternura, ele o conservou até a morte, mesmo nos dias longos e tenebrosos da loucura. Em 1887, dois anos antes de perder por completo a razão, escrevendo à sua mãe, ele se assina - tua velha criatura. E são os carinhos braços maternos que lhe vão acalentar a demência, na casa de saúde Basiléia, para onde fora transferido, de Turim, após a explosão de insânia que lhe 
enoitecera para sempre a inteligência. Em seus muitos dias, apenas duas silabas lhe movem os lábios: Mamãe, mamãe. É a invocação final, que nem a loucura conseguiria fazer amadurecer. Em seu livro - Humano, excessivamente humano - há o seguinte aforismo - o 380 -: Cada qual traz em si uma imagem da mulher, formada de acordo com a imagem da própria mãe; é por esse meio que é determinado as mulheres em geral, desprezá-las, ou lhes ser totalmente indiferente.

A imagem de sua mãe devia ser a de uma santa, em seu espírito. Porque julgava, então, criaturas inferiores às mulheres? Só o coração torturado poderia responder, em parte, à nossa curiosidade. Sua irmã Lisbeth atravessa, como um desvelado anjo da guarda, toda a sua existência, desde os dias lutuosos da infância até os seus últimos momentos. É a companheira de sua meninice; a consoladora de seus instantes de desalento; a enfermaria carinhosa, incansável de sua década de loucura. Nas montanhas dos Grisões e, no campo, junto à queda do Reno, em Basiléia, em toda parte Lisbeth surge, derramando as mãos cheias desse pobre coração, o bálsamo suave de sua delicada, e inexcedível amizade. Passeando um dia com o irmão, nos arredores de Flims, viram um pequeno castelo, que Nietzsche desejou adquirir. Percorreram a casa e firam encantados, planejando um futuro róseo na nova habitação: Terás necessidade de uma mulher para dirigir a casa disse Lisbeth; essa mulher serei eu. Mas o negócio não se realizou. A presença de sua irmã reanimava-o sempre.

Do campo, escrevia ele, certa vez, ao seu grande amigo, barão de Gersdorff: Minha está em minha companhia. Formamos, todo dia, os mais belos projetos para nossa vida futura, idílica, laboriosa, simples. Tudo vae bem! Desterrei toda tristeza, toda melancolia para bem longe... E passeava com a irmã, conversava, ria, sonhava e lia... De outra feita, sentia-se obcecado pela lembrança de seu amigo Romundt, que pretendia ordenar-se. Parecia-lhe uma traição, à sua amizade, esse ato do amigo.

Lisbeth chegava de Bayreuth para amenizar a tristeza profunda do irmão. Uma vez apenas, ligeira nuvem passou entre esses dois 
corações de irmãos que se adoravam. Nietzsche encontrara mãe e filha em discussão. Lisbeth queria casar-se com um tal Forster, agitador e ideólogo que organizava uma empresa de colonização no Paraguai. Sua mãe, que se opunha ao consorcio, apelou para Nietzsche, como uma salvação. Este falou com energia à irmã. Foi inútil toda a oposição.

Tempos depois, encontrou-se com Lisbeth, já casada, em Zurique. Abraçaram-se cordialmente. Lisbeth partira para o Paraguai. A correspondência entre os dois é sempre terna. "Vives longe, eu aqui, escreve-lhe Nietzsche, em uma solidão mais inatingível que todos os paraguais. Minha mãe deverá viver só e nós todos devemos ser corajosos. Eu vos amo e choro".

Do Paraguai, Lisbeth dá-lhe conselhos. Que se case. Nietzsche responde-lhe, em carta de 25 de Janeiro de 1888 (um ano antes da loucura) contando-lhe haver visto, num passeio, uma "jovem encantadora", cuja imagem não conseguia afastar de si, durante muito tempo. Lembra-se, então, dos conselhos matrimoniais da irmã, a quem escreve ainda: "Ser-me-ia, seguramente, benéfico ter a meu lado uma coisa tão graciosa. Mas para ela seria também um benefício? Acaso minhas ideais não tornariam infeliz essa jovem? Não teria eu coração despedaçado (supomos que eu a amaria) se visse sofrer tão amável criatura? Não, nada de casamento". É sempre nesse tom simples, confidencial, enternecido que ele se dirige a Lisbeth. E é nos braços dela que, 25 de Agosto de 1900, após dois lustros de loucura mansa, morreu, em Weimar, Frederico Nietzsche.

Melle. de Weysenbug dedicou a Nietzsche a mais sincera e desinteressada amizade.

Eles se conheceram em Bayreuth, onde o gênio de Wagner resplandecia, entre o culto ardente de seus discípulos e admiradores - um escol de artistas e homens de pensamento.

Melle. de Weysenbug tinha, então, 54 anos, e, apesar da idade, conservava ainda "esse encanto de ternura que jamais a abandonou e a graça física de um corpo frágil e nervoso". 
Pouco tempo depois ela publicava as suas "Memorias de uma idealista". Segundo Halevy, não era fulgurante a superioridade de espírito; era possuidora, porém, de um grande coração, e Nietzsche estimava muito essa mulher inteiramente fiel no verdadeiro gênio das mulheres.

O livro de Melle. de Weysenbug empolgou-o, como um dos mais belos testemunhos do século XIX. Ela na velha Alemanha, de uma de cujas pequenas cortes fora ministro seu pai. Ouvira, ainda criança, os amigos de Humboldt e Goethe. Moça, comovera-a pregação humanitária.

Deixara de observar o cristianismo e, um 1848, é seduzida pelo socialismo. Abandona os seus; funda uma escola comunista em Hamburgo. Perseguida pela polícia, foge para Londres, onde ganha a vida lecionando. Conhece Mazzini, Luiz Blanc e Herzen. Encontra-se com Wagner, de cuja música era admiradora. Troca pela arte o culto pela humanidade a que se voltara. Bayreuth a aproxima de Nietzsche. É uma amizade fraternal a que mutuamente se consagram. Nietzsche, muito mais moço, tem-lhe verdadeiro afeto filial, revelado nas cartas, que lhe escreve. Numa, em 1874, agradece-lhe um presente de flores. Noutra, de 1876, escrita de Basiléia, declara: "Um dos mais elevados temas morais que, graças a vós, descobri, é o amor materno sem vínculo físico entre mãe e o filho. É uma das manifestações magnificas da caritas. Concedei-me um pouco desse amor, cara senhora e amiga, e vede em mim um daqueles que têm necessidade de ser os filhos de tal mãe, ah! Tão grande necessidade!".

\begin{abstract}
Article published in 1922, in the journal A.B.C. In this text, which is an excerpt from the book Ideias e Comentários, Mario de Lima, talks about the role the women had in Nietzsche's life and work, in particular to the philosopher's relation with his mother, his sister Lisbeth and his friend Malwida von Meysenbug.
\end{abstract}

Keywords: Nietzsche - women - mother - sister - Malwida von Meysenbug 